\title{
Influence of Hydrogen on the Behaviour of 22MnB5 Steel
}

\author{
$1^{\text {st }}$ Lukáš Zuzánek $^{1}, 2^{\text {nd }}$ Jiří Sobotka ${ }^{2}, 3^{\text {nd }}$ Pavel Solfronk $^{3}, 4^{\text {nd }}$ Michaela Kolnerová $^{4}$ \\ lukas.zuzanek@tul.cz',jiri.sobotka@tul.cz²,pavel.solfronk@tul.cz michaela.kolnerová@tul.cz ${ }^{4}$
}

Technical University of Liberec, Liberec, Czech Republic, EU ${ }^{1,2,3,4}$

\begin{abstract}
The paper deals with the influence of the hydrogen on the behaviour of martensitic steel of type $22 \mathrm{MnB} 5$. Steels with the high yield strength reveal quite great predisposition for hydrogen present in the structure, so quite non-stable behaviour. Such behaviour increases with material loading, but can also occur even without acting of any outer forces. This process is termed as the hydrogen embrittlement and presents a great risk for structural parts in the whole industrial range. Because of utilization materials that are sensitive to the hydrogen embrittlement already in the advanced safety and strength applications, there is necessary to perform a lot of tests and analysis to eliminate hydrogen activity in metal structure before their application. There are mostly used mechanical tests which loaded sample by the tensile, bending or combine loading. Moreover, by utilization sophisticated devices, there is even possible to detect own hydrogen and determine its amount in the analysed structure.
\end{abstract}

Keywords: Hydrogen Embrittlement, Bending Loading, Climatic Chamber

\section{Introduction}

The creation of the hydrogen embrittlement represents the highest risk for materials with martensitic structure with ultimate strength (UTS) over $1000 \mathrm{MPa}$. Into them belongs also material 22MnB5. It's ultra high-strength steel that is in its basic state characteristic by ferritic-pearlitic structure with UTS $\left(R_{\mathrm{m}} 450-550 \mathrm{MPa}\right)$ and ductility $\left(A_{80}=\min 20 \%\right)$. These steels offer suitable properties for hot forming and high strength after thermal treatment (hardening), which is in process right in forming tool (PHS process). Such material property is given by adding a small amount of boron and manganese to increase hardenability and to prevent soft phases creation. Microstructure of boron steels after the thermal treatment is mainly created from the martensite and the retained austenite. [1] Samples, which were used in the experiment, were already after the thermal treatment, so revealed a martensitic structure with the following basic mechanical properties: $R_{m}=1800 \mathrm{MPa}$ and $A_{80}=5 \%$.

Nowadays, when are ultra high-strength materials quite widely used, great attention is also paid to research about influence of hydrogen on the construction materials that are commonly used not only in the automotive but also in other applications. Basic hydrogen atom (protium) contains one proton and one electron so it occupies the first place in the periodic table of elements. In the gas state of matter, hydrogen forms a diatomic molecule $\mathrm{H}_{2}$ that can't penetrate into material structure under the normal (room) temperature and pressure - so they do not have any influence in the properties of steel. Under the higher temperatures, humidity and pressure, on the steel parts surfaces occurs dissociation of hydrogen from the surrounding environment, where hydrogen in its atomic form very needs to find "partner" to create hydrogen bond and is why it is very reactive. In most cases, it bonds with another hydrogen atom to create molecule $\mathrm{H}_{2}$, which doesn't mean a risk for basic material. On the other hand, dissociated hydrogen is also able to bond with ferrum atoms on the steel surface and thus to create bond and penetrate into the material via diffusion process. Here, due to its very small dimensions, travels through lattice and here again tries to find "partner" of own kind to create molecule. During such motion through lattice, hydrogen very often sticks in the non-regularities inside the metal (inclusions, cavities, etc.), starts to cumulate there and especially it creates molecule of $\mathrm{H}_{2}$ which has very larger volume. The higher number of molecules, the higher internal stress and it can even result as own destruction of such part. Materials with the martensitic structure have low resistance against internal stress and that is why they represent a material group which is sensitive to the hydrogen embrittlement creation. A truly very dangerous environment, where can be found a lot of hydrogen and its subsequent diffusion into material, can be found during galvanic processes. Because of that, it is not recommended to electroplate materials with UTS over $1000 \mathrm{MPa}$. Fracture of part (material) that is caused by the hydrogen embrittlement occurs with some delay. Cracks are not created immediately after the production process, but after some time - hours or even weeks (it depends on the loading of given part). [2,4,5] 


\section{Principle of tests for determination the hydrogen embrittlement}

Basic test is based on the bending loading of flat samples of dimensions $100 \times 22 \times 1,5 \mathrm{~mm}$. Because of high hardness, shape of samples was given by the laser jet cutting with subsequent grinding of the cut edges to remove the heat affected zones. There were used two types of the environment for the experiment: standard atmosphere with room temperature and atmosphere with temperature $80^{\circ} \mathrm{C}$ and humidity $95 \%$. The second one was possible to prepare by climatic chamber. Testing samples were hardened and some of them already revealed so-called BH effect (bake hardening - there was applied thermal cycle at temperature $180^{\circ} \mathrm{C}$ for 20 min). After bending tests there was performed the thermos-evolution analysis to measure amount of diffusion hydrogen in the structure of material.

\subsection{Bending tests}

Testing samples were tested by the 3-point bending test in the testing jig (see Fig. 1). In this case force arises from the screw and deflection values are determined by the indicator. To precisely measure the loading force, there was used jig equipped with the force sensor (see Fig. 1 - left). Because of higher probability of hydrogen diffusion into the material, samples were put in the climatic chamber.
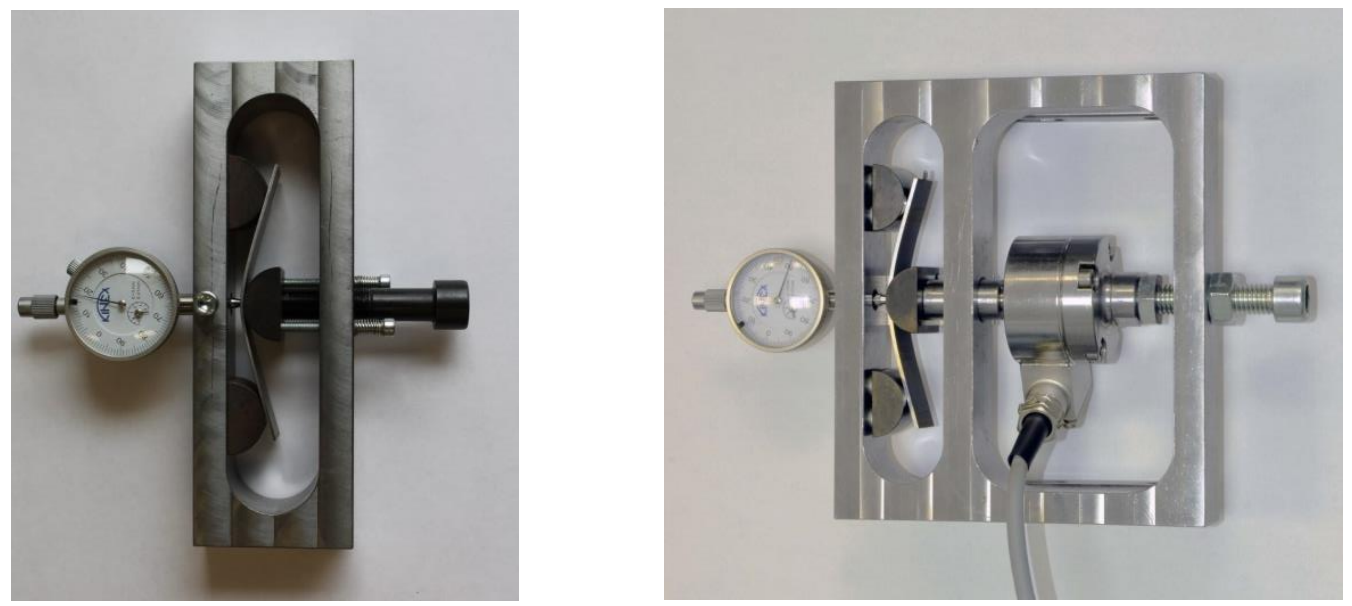

Fig.1 Jig for the bending loading (with the force sensor - right)

\subsection{Determination of the hydrogen amount in material}

In steels, hydrogen occurs only at trace concentrations; however it strongly influences their mechanical properties. Its content can be determine by different techniques - e.g. by the optical spectrometer emission. Nevertheless, as the most common and also the most sensitive method, there is thermos-evolution elementary analysis of solid substances. Nowadays is this method also termed as fusion in the inert gas. Sample is placed in the graphite cup and is heated (by resistance heating) in the furnace, where carrier inert gas flows - e.g. helium. Size of tested sample varies within the grams. Surface of sample should be treated to prevent results distortions. During heating of sample on the high temperatures (over $2000^{\circ} \mathrm{C}$ ), it melts which releases gases. These gases enter into the carrier gas flow and are analysed. Hydrogen is released in its elementary form as $\mathrm{H}_{2}$. Detection is performed on the base of carrier inert gas thermal conductivity change. In the Thermal Conductivity (TC) detector is analysed gas led over the heated filament that is cooled down by it. TC detectors are not selective (in contrast to IC detectors) which means that every component of that compound contributes to its total thermal conductivity. That is why, there is detected only one gas and other gases have to be removed from the original compound. For example molecular sieves are used to remove hydrogen and nitrogen. At the end, final measured values are within the scale of ppm units. [3] 


\section{Evaluation of the experiment}

First part of the experiment was performed on the jig designed for bending loading (see Fig. 1). As a major aim, there was to measure the dependence of environment and loading influence on the behaviour of the hydrogen embrittlement. To clarify the results from bending tests, the same samples were subsequently tested to analyse content of the diffusion hydrogen in the material structure

\subsection{Results from the bending tests}

Because there was aim to clarify whether at higher temperature and humidity can be changed tested samples behaviour, experiment was carried out in two environments. First tests were performed in the standard environment (room temperature) and after that were samples together with the testing jigs put into the climatic chambers at temperature $80^{\circ} \mathrm{C}$ and relative humidity $95 \%$. Higher temperature and humidity was used to increase probability when hydrogen from the surrounding environment can dissociate on the surface and subsequently can diffuse into the material structure. There were used two bathes of samples: in the first batch were samples in the basic hardened state and in the second one were already after BH process. For every test there were used four samples to eliminate possible errors created during the experiment.

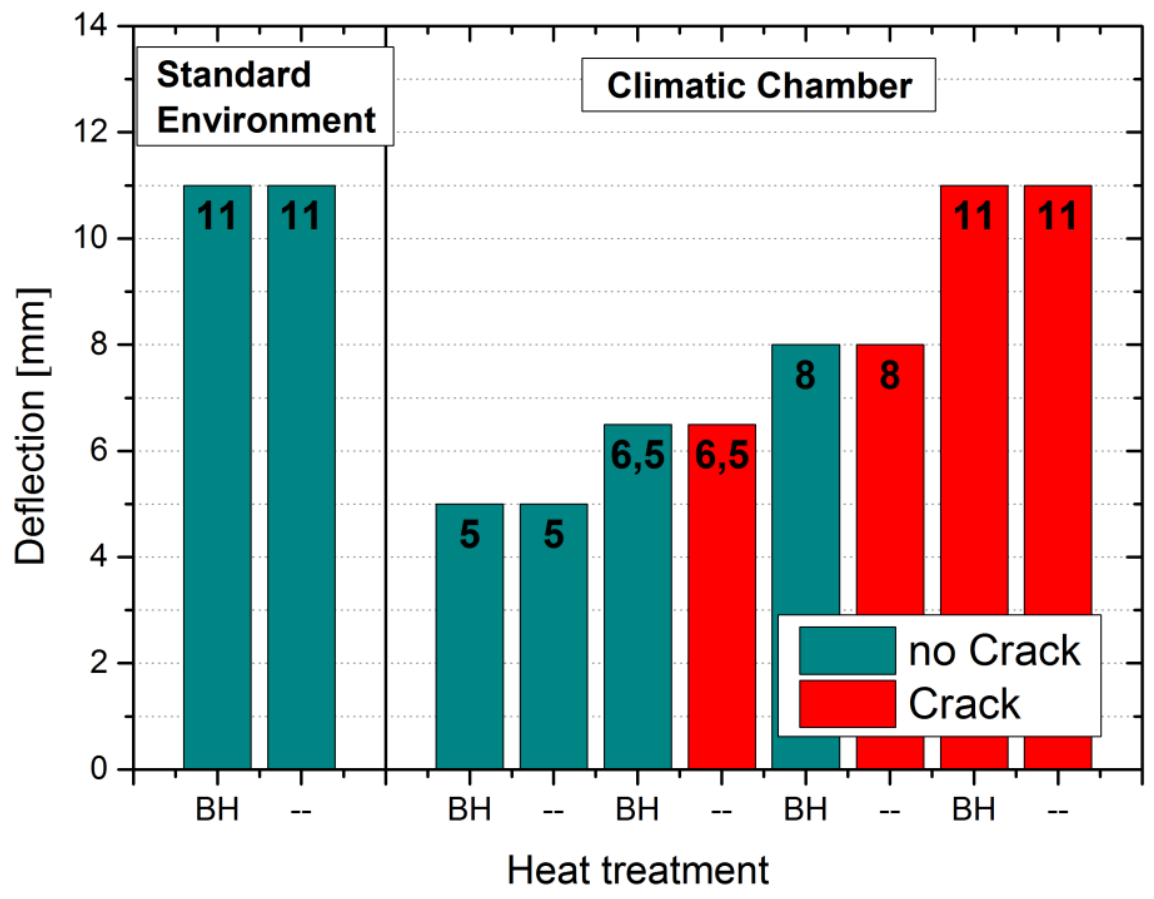

Fig. 2 Influence of environment and thermal treatment of testing sample on the material behaviour

In Fig. 2 are shown results of tests in the dependence on the deflection value, used environment and $\mathrm{BH}$ effect. For the standard environment and sample deflection of $11 \mathrm{~mm}$, there wasn't crack of sample and also any fractures weren't observed for material both in the basic state and after BH process.

On the other hand, both tested batch of samples (basic state and after BH effect) cracked in the climatic chamber under deflection of $11 \mathrm{~mm}$. At deflection of $8 \mathrm{~mm}$ was observed a different behaviour between material in the basic state and after BH process. There wasn't fracture for material after BH process. In contrast to that, material in the basic state fractured. The same trend was observed also at deflection of $6,5 \mathrm{~mm}$. The stable values (without fracture of any material) were achieved at deflection of $5 \mathrm{~mm}$. From Fig. 2 is evident such negative influence of the environment with higher temperature and relative humidity. As a major reason for that, there is low-temperature tempering during the thermal treatment (BH effect). 


\subsection{Determination of hydrogen content in steel by the thermal-evolution analysis}

To clarify and find the reason of non-uniform behaviour os samples, for own analysis there were used samples from the previous tests (after bendign tests). From these results is evident, that there is diffusion of hydrogen into material at placing sampels in the climatic chamber. In comparison to the standard environemtn (room temperature), hydrogen content increased by approx. 1 up to 1,3 ppm. Difference between hydrogen contetn for samples with basic state and after BH effect is not significant at placing samples in the stadard environemnt. However, in the climatic chamber samples after BH effect revelaed its increase by $0.5 \mathrm{ppm}$.

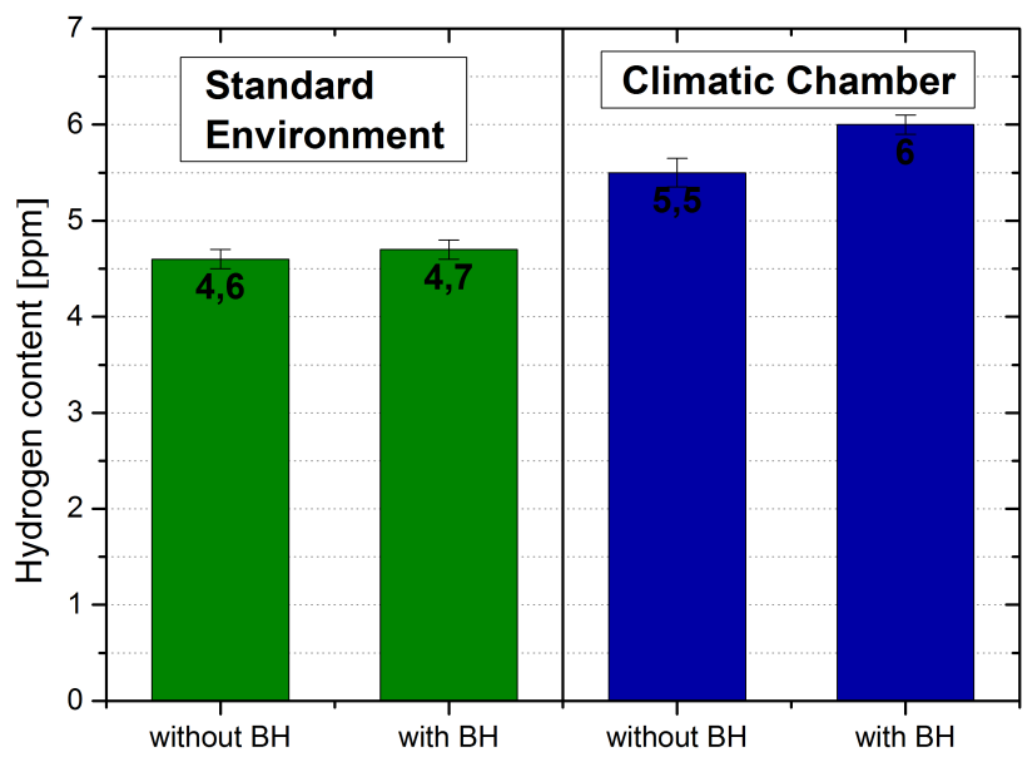

Fig. 3 Influence of environment and thermal treatment of testing sample on the hydrogen content in the material

\section{Conclusion}

Based upon the performed tests can be obviously observed influence of the surrounding environment on the hydrogen diffusion into the material structure which results in its lower resistance against loading. From the bending tests point of view, there were fractures of samples at higher temperature and relative humidity. However, this wasn't observed at placing samples in the standard environment. BH process increases material resistance against fracture - there wasn't fracture of sample at deflection of $8 \mathrm{~mm}$, but such value was no more than $5 \mathrm{~mm}$ for material without BH effect. It rests in the low-temperature tempering which results in lowering of the internal stress and small increase of ductility. Thermo-evolution analysis also proved the higher ability of hydrogen absorption in the climatic chamber. That's why finally can be stated that for parts which are placed in the environment of higher humidity, there is necessary to take into account possible risk of cracks creation up to final fracture of these parts. Based on these results, it would be possible to establish a precise measurement methodology that would detect the formation of hydrogen embrittlement. The methodology would be based on the tests described in the article which would define limit values for the load and the hydrogen content of the tested material.

\section{Acknowledgements}

This publication was written at the Technical University of Liberec as part of the Student Grant Contest "SGS 21121" with the support of the Specific University Research Grant, as provided by the Ministry of Education, Youth and Sports of the Czech Republic in the year 2017. 


\section{References}

[1] Davies, G. Materials for Automobile Bodies. Oxford: Butterworth-Heinemann, 2003. p 277. ISBN 0-75065692-1

[2] Yukitaka, M. Toshihiko, K.. Yoji, M. Saburo, M. Hydrogen Embrittlement Mechanism in Fatigue of Austenitic Stainless Steels, Metallurgical and Materials 2008, Volume 39, pp.1327-1339, ISSN: 1073-5623

[3] Praus, P. Vontorová, J. Analytická chemie II. 1 vyd, Ostrava VŠB - Technická Univerzita Ostrava, 2015, 158 s., ISBN 978-80-248-3734-5

[4] Bhadeshia H, K. Prevention of Hydrogen Embrittlement in Steels, ISIJ International 2016. Vol 56. pp. 2436, ISSN: $1347-5460$

[5] Sofronis,P. Nagao,M.,Martin,M,L. Wang,S. Gross,D,W. Nygren,K,E. Hydrogen Embrittlement Understood, Metallurgical and Materials Transactions A, June 2015, Volume 46, Issue 6, pp 2323-234, ISSN: $1543-$ 1940 